\title{
Chapter 11 \\ Conclusions
}

After completing our case study through behavioral observations and histological observations of the sections of ovary, testis, and pituitary gland of control as well as experimental fishes, we have concluded that not only for guppy but putting in view all the fishes are being harmed at a very huge and large level.

Hormonal level has been altered, and in turn it is affecting the normal functioning of other target organs. Gonadotropic hormones are affected which in turn affect the normal functioning of gonads and parturition.

Fishes like major carps lay eggs over lacs, and these eggs develop into fishes and provide a rich source of proteins at very cheap price.

Due to the impact of industrial effluents, the spermatogenesis and spermiogenesis are arrested; as a reason a few thousand spermatogonia reach the stage of spermatids and sperms. This affects the sperm count of the male fish and in turn affects the fertilization rate of the eggs of female. This directly affects the number of spawn.

Also the effluent has degenerating effect on the eggs; more of the eggs become atretic or get degenerated. This affects the egg-laying capacity of the females. A female which was producing one lac eggs per parturition now gives $50 \%$ of the egg count or fecundity.

If the pollution problem continues and increases in such a manner, the fecundity will reduce to $75 \%$ than $90 \%$, and after sometime there will be extinction of the fish species from the aquatic world.

Most of the fish species are on the verge of becoming extinct and pollution is the main reason for this calamity.

Overfishing does affect the fish population but not the fecundity; pollution directly affects the species, and if this continues most of the fish species will be extinct, and we will have luxurious life but not healthy food to eat.

If effluent has to be drained in water bodies or land, it must be treated and then drained or reused. Reusing the treated water is the best option and beneficial for all. 